\title{
Las mujeres y la guerrilla: ¿un espacio para las políticas de género?
}

\section{Women and guerrila: a space for a gender agenda?}

\author{
Carolina Jiménez Sánchez ${ }^{1}$ \\ Universidad de Málaga (España)
}

Recibido: 26-03-14

Aprobado: 11-04-14

\section{Resumen}

El presente artículo examina la naturaleza de la guerra de guerrillas desde una perspectiva de género y con una especial consideración de su impacto en los diversos escenarios iberoamericanos en los que se libró o se libran luchas armadas con la intervención de grupos guerrilleros. Igualmente, se tomará en consideración la incorporación de las mujeres a la guerrilla y los papeles que éstas han desarrollado en los mismos. Dada la heterogeneidad de la guerra de guerrillas en los diversos contextos, el presente artículo toma dos modelos de análisis comparativo: las guerrilleras del Ejército Zapatista de Liberación Nacional (EZLN) y las guerrilleras de las Fuerzas Armadas Revolucionarias de Colombia (FARC).

Palabras-clave: mujeres guerrilleras, guerrilla, perspectivadegénero, políticas de género.

\footnotetext{
${ }^{1}$ (carolina@uma.es) Carolina Jiménez Sánchez es profesora ayudante de Derecho Internacional Público en la Facultad de Derecho de la Universidad de Málaga y tutora de la UNED en Derecho Internacional Público y Derecho de la Unión Europea. Consiguió la suficiencia investigadora en 2009, con un trabajo de investigación sobre terrorismo y derechos humanos. En 2010 presentó la tesina de licenciatura "La subjetividad internacional del Frente POLISARIO", obteniendo la licenciatura en grado. Es Máster en Estudios Internacionales y de la Unión Europea por la Universidad de Valencia y miembro del proyecto de investigación "Colectivos en los márgenes: su exclusión por el derecho en tiempos de crisis (DER-2012-34320), dentro del cual se enmarca esta publicación. En 2013 obtuvo el grado de doctora con una tesis sobre género y conflictos armados.

Entre sus publicaciones recientes destacan: "Nuevos marcos del Terrorismo Internacional: el fenómeno de las Female Suicide Bombers", en La seguridad internacional en el siglo XXI. Nuevas perspectivas, GARCÍA RICO, E. del M.; TORRES CAZORLA, M. I (Coords.), Madrid, 2011; “Gender Mainstreaming in Peacekeeping Operations: Successes and Mistakes, Transitional Justice Institute Research Paper, Vo.l. 12-08, 2012; "La protección internacional de los derechos humanos de las mujeres. Una visión desde la multiculturalidad y la perspectiva de género", (Junto con MARTÍN MARTÍNEZ, M.), en Diversidad Cultural, Género y Derecho, (LAURENZO COPELO, P.; DURÁN MUÑOZ, R., Coords.), Tirant lo Blanch, Valencia, 2013.
} 


\begin{abstract}
This article examines the nature of guerrilla warfare from a gender perspective and with special focus of their impact on the various scenarios in past or present of Latin American armed struggle, even more other experiences in different regions will be also examined. Likewise, it will consider the incorporation of women to the guerrillas and what are the roles they have developed in them. Considering the heterogeneity of guerrilla warfare in various contexts, this article takes a comparative analysis of two models: the guerrillas of the EZLN (Ejército Zapatista de Liberación Nacional) and the FARC (Fuerzas Armadas Revolucionarias de Colombia).
\end{abstract}

Key-words: guerrilla women, guerrilla warfare, gender perspective, gender agenda.

\title{
La construcción del grupo guerrillero
}

Los conflictos armados han experimentado una transformación notable desde el siglo XX hasta el XXI. Numerosas variables influyen en que éstos sean cada vez más complejos, sus causas más subterráneas, sus actores más abstractos, sus márgenes más difusos y su catalogación siempre controvertida.

La guerra de guerrillas presenta particularidades evidentes en sus medios y métodos de lucha, como grupo irregular de combatientes. Sin embargo, estas singularidades no son sino una consecuencia de su posición de inferioridad con respecto a ejércitos regulares estatales. Con esta visión relativista alcanzaremos a comprender hasta dónde llegan los aspectos concretos que la diferencian de otros fenómenos bélicos.

Atendiendo a la catalogación de los guerrilleros como combatientes o a sus medios y métodos de combate advertiremos peculiaridades propias de la guerrilla, lo que también sucede en su construcción como grupo, donde se observan rasgos distintivos como consecuencia de la posición extra-estatal que caracteriza este método de lucha. La carencia de un sistema de reclutamiento oficial puede delinearse como una de las señas de identidad de la guerrilla: la exhortación a la población civil a unirse a la misma. Y es que, en ocasiones, la guerrilla ha sido vista como la guerra del pueblo, y es por ello que los guerrilleros llaman a las armas a su pueblo en pro de una causa que creen justa, un fin último para el que el medio elegido es la lucha armada.

Esta circunstancia lleva a que la práctica totalidad de los guerrilleros provenga de la población civil, en su mayoría de zonas rurales, sin entrenamiento previo en actividades bélicas. En este sentido, es necesario apreciar que, al contrario que otros grupos armados, en la población civil no se margina a un 
sexo sobre otro. Ya que la misma está compuesta por hombres y mujeres, ambos son el objetivo de reclutamiento de las guerrillas.

Esto supone que la guerra de guerrillas presenta particularidades también en su interacción con las realidades de género, algunas de las cuales serán objeto de análisis en este artículo. El cambio de óptica en algunos aspectos de los esquemas patriarcales en este tipo de lucha armada es una de las señas que particularizan su composición como grupo.

En efecto, si tradicionalmente se ha considerado al hombre como guerrero, el papel de la mujer en el conflicto armado venía reducido al de víctima. No obstante, si echamos un vistazo al pasado reciente, existen abundantes ejemplos de mujeres combatientes en las zonas de guerra, tanto de las Fuerzas Armadas regulares como de grupos insurgentes o milicias irregulares, lo que también debería aportarnos una visión de la mujer guerrera, aunque, en cualquier caso, y según la óptica con la que se trate, los guerreros son también inequívocamente víctimas de las contiendas. En consecuencia, aunque las mujeres han adoptado papeles multilaterales en los conflictos armados, sobre ellas se ha cristalizado un victimismo excluyente, que la aleja del reconocimiento de la asunción de otros papeles que, efectivamente, han venido asumiendo en mayor o menor medida. En el caso concreto de la guerrilla esta invisibilización queda atrás, precisamente por la naturaleza del grupo guerrillero, que pretende aglutinar a todo el "pueblo", dejando en un segundo plano la delimitación férrea de los roles arquetípicos.

\section{Papeles e identidades de las mujeres en la guerrilla}

Las mujeres han formado parte de la guerrilla desde siempre, si bien los roles que desempeñaban en ésta han ido desde el de vivandera ${ }^{2}$ o mera colaboradora externa hasta el de combatiente, aunque en ocasiones los roles más destacados eran invisibilizados por sus propios compañeros ${ }^{3}$. Es precisamente a partir de los años sesenta del siglo XX, con el auge de los movimientos guerrilleros en Iberoamérica, cuando las mujeres toman un papel fundamental en la insurgencia ${ }^{4}$. Las influencias comunistas que llegaban desde Cuba y la oposición a la Guerra de Vietnam ofrecieron el clima de tensión política adecuado para teñir a gran parte del continente de una esperanza revolucionaria que culminaría en la creación de numerosos grupos insurgentes que basaban su lucha en la guerra de guerrillas.

\footnotetext{
${ }^{2}$ La "vivandera" es la persona encargada de proporcionar los víveres a los militares en campaña.

${ }^{3}$ María Eugenia Ibarra Melo, Mujeres e insurrección en Colombia: reconfiguración de la identidad femenina en la guerrilla, Pontificia Universidad Javeriana, Cali, 2009, 240, pág. 94 y s.s.

4 Jane Jaquette, "Los movimientos de mujeres y las transiciones democráticas en América Latina", en Magdalena León, coord.: Mujeres y participación política. Avances y desafios en América Latina, Bogotá, Tercer Mundo Editores, 1994, pág. 117-139.
} 
A su vez, estas organizaciones, influenciadas por las políticas soviéticas y chinas, introducían en la organización de sus movimientos estrategias como la bolchevización, los pies descalzos o la proletarización, según las cuales era necesaria la profesionalización dentro de la revolución, para lo que los individuos debían dejar sus empleos y oficios y unirse a tiempo completo a la revolución ${ }^{5}$.

En este marco, el papel reservado a las mujeres volvía a ser limitado. Las políticas comunistas las contemplaban como un instrumento al servicio del hombre, que era el protagonista de la revolución. Su cometido era el de conseguir el mantenimiento económico de los dirigentes políticos revolucionarios. Ejemplos de la aplicación de estas prácticas se encuentran en las revoluciones de México (con la Adelita) o Colombia, donde la imagen de las mujeres revolucionarias no escapaba en sus comienzos de los sacrificios del trabajo y el servicio a un líder ${ }^{6}$.

Hay que subrayar que ya desde este primer momento las mujeres habían hecho ejercicio de su libertad; en este caso de elección política e ideológica, lo que conlleva un cambio en su propia identidad y un aumento de la concepción propia de su papel en la sociedad. La mujer pasaba de tener un papel doméstico y, por lo tanto, familiar, ignorado y oculto, a tener en mayor o menor medida un papel social, que resultaba de vital importancia para la consecución de los fines del grupo.

Pese a que lo lógico hubiera sido que el papel de las mujeres en la guerrilla hubiera ido en progresivo aumento, el triunfo de la revolución en Nicaragua fue suficiente para evidenciar ante la organización popular que la participación de las mujeres era secundaria y en absoluto necesaria para alcanzar la victoria final ${ }^{7}$. Es en este escenario donde las mismas mujeres se repliegan, uniéndose en estas ocasiones entre ellas para tratar los problemas comunes, creando movimientos feministas paralelos a la guerrilla que, sobre todo en Colombia, tuvieron especial importancia, ya que sus resultados fueron posteriormente aplicados a las políticas estatales ${ }^{8}$.

Poco después, las mujeres comienzan a incorporarse a las guerrillas progresivamente, y esto sucede con un régimen de acceso peculiar, existiendo diferentes modelos, sobre todo según la época y la clase social de las mismas. En algunos casos, como en El Salvador, la euforia social y la conciencia ante las represiones gubernamentales fueron causa suficiente para el alistamiento en los grupos guerrilleros. Aunque en estos casos estamos hablando de mujeres urbanas, quienes sentían una necesidad para con la sociedad y se alistaban voluntariamente.

${ }^{5}$ Estas directrices responden a las contenidas en lo relativo al Partido de Profesionales de la Revolución de Lenin.

${ }^{6}$ Evelyn Cherpack, "Las mujeres en la independencia", Las mujeres en la historia de Colombia: Tomo II Mujeres y Sociedad, Santa Fé de Bogotá, Consejería Presidencial para la Política Social.

${ }^{7}$ M. Molineux, “¿Movilización sin emancipación?, Intereses de la mujer, El Estado y la revolución: El caso de Nicaragua", en Nuñez La Transición dificil: la autodeterminación de pequeños países periféricos, Orlando Nuñez et. al. (Ed.), Managua, Vanguardia, 1987, pág. 34.

${ }^{8}$ Es en esta época cuando se produce el Primer Encuentro de Mujeres Latinoamericanas y del Caribe, que tuvo lugar en Bogotá en 1981. 
Caso diferente fue el de las mujeres rurales, para las que las ideologías políticas tenían poco calado y su llegada al grupo solía producirse de manera forzada, frecuentemente por sus propias familias o bien por circunstancias de necesidad. En contadas ocasiones la incorporación de mujeres rurales salvadoreñas constituyó una opción individual, produciéndose, en la mayoría de los casos, a través de procesos de decisión colectivos, donde los hombres dominaban las estructuras de poder tanto familiares como sociales.

En otras regiones del planeta encontramos casos singulares, como el de las guerrilleras en Zimbabwe en la década de los 70. Como apunta Lyons, "Zimbabwean women guerrilla fighters were hailed internationally as women who rose above traditionally subordinate gender positions in order to fight equally with men in the struggle for national independence" . Algo similar sucedía en otras guerrillas africanas que llegaron a cobrar sentido como símbolo de la liberación femenina en otras partes del mundo, aunque en ningún caso aseguró la igualdad automática de las mujeres en los frutos cosechados por la revolución. Así, sigue Lyons: "Internationally, socialist feminist expected that women in southern Africa would be liberated as their nations gained independence" ${ }^{10}$. De igual manera, es necesario destacar el papel de las mujeres guerrilleras en la España de la Resistencia antifranquista ${ }^{11}$. En todos estos casos las mujeres ganaron eventualmente algunas posiciones en las sociedades de la postguerra, aunque la palabra igualdad quedaba lejos de la realidad ${ }^{12}$.

En cuanto a las guerrillas de liberación, se calcula que hasta una tercera parte de los Tigres de Liberación de Eelam Tamil (LTTE) que luchaban por la independencia de Sri Lanka, eran mujeres ${ }^{13}$. También en las guerras de liberación colonial que tuvieron lugar en África en las décadas de los 60, 70 y 80 jugaron un importante papel: Mozambique o Namibia son ejemplos de ello ${ }^{14}$. Especialmente relevante fue la contribución de las mujeres en Sudáfrica, en las fuerzas del African National Congress (ANC), así como en las guerrillas Mau-Mau en Kenia con un $5 \%$ de los efectivos ${ }^{15}$, y constituyeron también un destacado $25 \%$ del total del ZANLA en Zimbabwe ${ }^{16}$.

\footnotetext{
${ }^{9}$ Tanya Lyons, "Guerrilla Girls and Women in the Zimbabwean National Liberation Struggle", en [Jean Allman; Susan Geiger; Nakanyike Musisi, coords.: Women in African Colonial Histories, Bloomington, Indiana University Press, 2002], pág. 338.

${ }^{10}$ Ibídem., pág. 306.

${ }^{11}$ Francisco Moreno Gómez, "Guerrilleras y Enlaces: Las mujeres en la resistencia antifranquista", Andalucía en la Historia, 25, (2009), págs. 26-29.

12 Vid., Stephanie Urdang, And Still They Dance: Women, War, and the Struggle for Change in Mozambique, London, Earthscan, 1989, pág. 256.

${ }^{13}$ Op. cit., p. 576.

${ }^{14}$ Signe Arnfred, "Women in Mozambique: Gender Struggle and Gender Politics", Review of African Political Economy, vol. 15, 41, (1988), págs. 5-16.

${ }^{15}$ Sharon Macdonald, Shirley Holden, Patt Ardener, Images of Women in Peace \& War. Cross Cultural \& Historical Perspectives, UK, The Macmillan Press, 1987, págs. 89 y ss.

${ }^{16}$ Sobre las mujeres en la guerra de liberación nacional de Zimbabwe Vid: Tanya Lyons, Guns and Guerrilla Girls. Women in the Zimbabwean Liberation Struggle, Asmara, Africa World Press, 2004, pág. 319.
} 
Un caso especialmente significativo fue el que tuvo lugar en 1975 en Tigray, provincia de Etiopía, donde el Frente de Liberación del Pueblo de Tigray (TPFL) movilizó a las mujeres en la lucha por la autodeterminación, proveyéndolas además de acciones positivas de género, al facilitar su participación con la gestión de guarderías y proporcionándoles educación militar y política ${ }^{17}$.

En este sentido, al margen de que tanto para las mujeres como para los hombres de pueblos sometidos a dominación colonial o extranjera el objetivo era el mismo, la libertad, las mujeres encontraron en muchos casos otro tipo de motivaciones relacionadas con la lucha por la igualdad de sexos y la reivindicación de sus derechos ${ }^{18}$. De ahí que se hayan derivado grupos de mujeres feministas dentro de los propios movimientos de liberación nacional. Entre ellos la General Union of Palestinian Women, que publicó en 1994 la Declaration of Principles on Palestinian Women 's Rights ${ }^{19}$, texto que garantiza una catálogo general de Derechos Civiles, o la Unión Nacional de Mujeres Saharauis, organización vinculada al Frente POLISARIO y creada en 1974 por y para las mujeres del Sáhara Occidental ${ }^{20}$. Entre sus actividades se encuentra la reivindicación de los derechos de las mujeres y la sensibilización y concienciación sobre los propios derechos, dentro del contexto de la lucha por la autodeterminación. El papel de las mujeres saharauis adquirió especial relevancia durante el inicio del conflicto armado en 1975, cuando éstas tuvieron un papel principal en la creación de los actuales campamentos de refugiados en Tinduf (Argelia), después de huir de los bombardeos con napalm y fósforo blanco que asestaba el Ejército marroquí ${ }^{21}$. Una labor especialmente relevante tanto en la época de la lucha armada como en los más de veinte años desde el alto el fuego de $1991^{22}$.

${ }^{17}$ Olivia Bennet; Jo Bexley; Kitty Warnok, Arms to Fight, Arms to Protect: Women speaks out about conflict, London, Panos Publications, London, 2001, pág. 288.

18 Christine Chinkin, "A Gendered Perspective to the International Use of Force", Australian Yearbook of International Law, 12, (1988-1989), pág. 279-293.

19 Declaration of Principles on Palestinian Women's Rights, en: http://www.watcpal.org/english/ display.asp?DocID=7.

${ }^{20}$ Se puede visitar su página web en: http://www.arso.org/UNMS-1.htm.

21 Sobre la historia del Sáhara Occidental Vid. José Ramón Diego Aguirre, Historia del Sáhara español: la verdad de una traición, Madrid, 1998, pág. 879.

22 Desde que en 1991 se decretara el alto el fuego, los avances hacia una solución definitiva para la autodeterminación del pueblo saharaui han sido inexistentes, por lo que hoy es un conflicto estancado que las Naciones Unidas han preferido reactivar mediante el recurso "infinito" de la negociación de las partes. 


\section{La inclusión de políticas de género en los movimientos guerrilleros: comparación de modelos}

Debido a la presencia de grandes diferencias entre unas y otras guerrillas, a continuación vamos a centrar el análisis en dos casos concretos en el contexto iberoamericano, en orden a comprender mejor el fenómeno de las mujeres guerrilleras, evitando del mismo modo adoptar una postura generalista que englobe las políticas guerrilleras.

En concreto, el análisis está centrado en la aparición de políticas de género en el interior de los grupos guerrilleros, examinando cómo han influido éstos en los roles de género tradicionalmente atribuidos y, en general, en la posición y conciencia social de las mujeres Iberoamericanas. Como veremos seguidamente, los casos de México (EZLN) y Colombia (FARC) se perfilan como buenos reflejos de los diferentes modelos de las políticas de género adoptadas por los grupos guerrilleros.

\section{a) Guerrilleras en el Ejército Zapatista de Liberación Nacional (EZLN)}

Los modos de acceder al Ejército Zapatista de Liberación Nacional (EZLN), en México, estaban fuertemente guiados por las pautas de clandestinidad, involucrándose lentamente los miembros de las comunidades rurales e indígenas a través de un proceso gradual de confianza en el grupo. Además, esta confianza se reforzó con los llamados Comités Clandestinos Revolucionarios, cuyos dirigentes eran precisamente los líderes indígenas. Dado este indigenismo tradicionalista, el acceso a las mujeres en el EZLN era más complicado, pero también resultó ir progresivamente en aumento, y a lo largo de los años el EZLN implementó una auténtica política de género. Asimismo, es de subrayar que el ingreso constituía una elección totalmente voluntaria para las mismas.

Para formar parte de la guerrilla las mujeres debían presentarse ante el Comité, y éste debía elegirlas democráticamente, lo que sin duda supuso una apertura para un grupo tan tradicional. Podían formar parte del grupo de dos maneras: o bien como militares o como bases políticas de apoyo ${ }^{23}$. Formar parte de cualquiera de estas modalidades de participación en el EZLN no suponía una subordinación a la figura masculina, sino una cooperación para con unos ideales que eran compartidos ${ }^{24}$.

${ }^{23}$ Sarri Vuorisalo-Tiitinen, ¿Feminismo indigena? Un análisis crítico del discurso sobre los textos de la mujer en el movimiento zapatista 1994-2009, Helsinki, University of Helsinki, 2011, pág. 310.

${ }^{24}$ Enrique Pérez, Resistencia y participación política de las mujeres indígenas de los Altos de Chiapas (San Andrés de Sacamchén) (Larraínzar) y San Pedro Chenalho) 1994-2000, Tesis Doctoral, Universidad Nacional Autónoma de México, 2002, pp. 138-139. 
Pese a que el número de mujeres en el EZLN no era excesivo, éstas sí ocupaban cargos de responsabilidad; uno de los ejemplos más significativos era el de la Mayor de Infantería, Ana María, una mujer tzotzil que se encargó de tomar posesión de la ex capital del Estado de Chiapas, San Cristóbal de las Casas, lugar estratégico para la lucha zapatista. También destacó con un importante papel dentro de la organización la Comandante Ramona, artífice de los primeros diálogos de paz con el gobierno mexicano. Sin embargo, su nombre pasó al olvido al convertirse su inferior, el Subcomandante Marcos, en la voz y la imagen de la prensa internacional ${ }^{25}$. Como podemos observar, tanto la Mayor de Infantería como la Comandante han pasado inadvertidas, a pesar de los muy relevantes papeles que tienen en la organización.

Todavía hoy se manifiesta una marcada ideologización de los sexos en la instrucción militar y otros aspectos de los grupos armados. Sin embargo, en este punto hay que subrayar que el EZLN constituye una excepción, al implementar políticas de género en su reglamento.

Antes de eso el grupo tenía algunas normas férreas y estrictas que afectaban directamente a las féminas. Una de las normas con la que las combatientes estaban descontentas era la que establecía que cuando una mujer se quedaba embarazada tenía que elegir obligatoriamente entre dos posibilidades: abortar y seguir siendo combatiente activa del grupo, o seguir adelante con el embarazo, y tener y criar a su hijo fuera de las armas. Las mujeres reclamaban el derecho de tener a sus hijos y decidir voluntariamente seguir en las armas.

A pesar de que este derecho aún no les ha sido otorgado, la reivindicación sirvió a las mujeres del grupo para crear la Ley Revolucionaria de las Mujeres, en la que reclamaba justicia e igualdad para las mismas dentro el grupo pero también a lo largo de todo México, por lo que se ha intentado que la ley sea de aplicación general. La Ley contempla los siguientes puntos:

1. Las mujeres, sin importar su raza, credo, color o afiliación política, tienen el derecho de participar en la lucha revolucionaria de la manera que sus deseos y habilidades se lo determinen.

2. Las mujeres tienen el derecho de trabajar y recibir un salario justo.

3. Las mujeres tienen el derecho de decidir el número de hijos que tendrán y criarán.

4. Las mujeres tienen el derecho de participar en los asuntos de la comunidad y de tener posiciones de autoridad si son electas de manera libre y democrática.

5. Las mujeres y los niños tienen el derecho a la atención primordial en asuntos de salud y nutrición.

6. Las mujeres tienen el derecho a la educación.

${ }^{25}$ M. C., "El papel de las mujeres zapatistas en el EZLN", Historia, Julio, 2008. Accesible en: http://autorneto.com/referencia/historia/el-papel-de-las-mujeres-zapatistas-en-el-ezln/. 
7. Las mujeres tienen el derecho a elegir su pareja o cónyuge y no se las obligará a casarse.

8. Las mujeres no serán golpeadas o maltratadas físicamente por miembros de su familia o por extraños. La violación y el intento de violación serán castigados severamente.

9. Las mujeres podrán ocupar posiciones de liderazgo en la organización y podrán ocupar rangos militares en las fuerzas armadas revolucionarias.

10. Las mujeres tendrán todos los derechos y obligaciones elaborados en las leyes revolucionarias ${ }^{26}$.

Este catálogo de derechos iba a tener repercusiones directas en la conciencia de las mujeres de todo México, quienes consideraban que una mujer zapatista tenía más derechos que una que no lo era y, consecuentemente, menos obligaciones derivadas del modelo patriarcal. La vida para las mujeres en Chiapas no era fácil en los años noventa, momento en el que existían grandes convicciones sociales y morales sobre los papeles de las mismas en la comunidad ${ }^{27}$. Eran prácticas comunes el matrimonio forzado, los abusos sexuales antes y durante el matrimonio o la prohibición de bailar en público para las casadas. Es por ello que esta política progresista del EZLN trajo el alistamiento de muchas mujeres de la región, quienes deseaban evitar verse obligadas al acatamiento de estas y otras normas sociales. Igualmente, los zapatistas terminaron por convertirse en bandera de las mujeres de todo México, a quienes apoyaban en sus reclamaciones de libertad, justicia y trabajo ${ }^{28}$.

En este sentido, Alberti ha distinguido tres etapas en el discurso de las mujeres indígenas que podemos ver reflejado concretamente en la Ley Revolucionaria expuesta: 1) discurso de la unidad global; 2) discurso de la conciencia de género; y 3) discurso crítico de género y etnia ${ }^{29}$. En el discurso zapatista se aprecia nítidamente la primera de estas fases, en la que el grupo intenta ser percibido como una sola voz, dejando a un lado las reivindicaciones específicas ${ }^{30}$ para luego pasar a considerar las cuestiones de género, tal y como se aprecia en la Ley Revolucionaria.

${ }^{26}$ Estas normas se pueden encontrar en: Mercedes Olivera, "El Ejército Zapatista y la liberación de las mujeres chipanecas", Centro de Estudios Miguel Enríquez, 1995, accesible en: http://www. archivochile.com/Mov_sociales/mov mujeres/doc muj_otros/MSdocmujotros0011.pdf.

${ }^{27}$ Guiomar Rovira, Mujeres de Maiz. La voz de las indigenas de Chiapas y la rebelión zapatista, Barcelona, Virus, 1999, pág. 236.

${ }^{28}$ M. C., El papel..., op. cit.

${ }^{29}$ P. Alberti Manzanares, "El discurso polifónico acerca de las mujeres indígenas en México: académicas, gobierno e indígenas", en [S. Pérez Gil, P. Ravelo, coords.: Voces disidentes. Debates contemporáneos en los estudios de género en México, Ciesas-Porrúa, México, 2004], págs. 183-220.

${ }^{30}$ Sarri Vourisalo-Tiitinen, "Un análisis crítico del discurso sobre el problema del ser mujer e indígena en México-La respuesta de las mujeres zapatistas a la reestructuración neoliberal”, en [Género y globalización en América Latina: décimo aniversario de la Red Haina (1996-2006), Göteborg, Universidad de Göteborg, 2007], pág. 197. 
Podemos concluir que el EZLN es un grupo que ha integrado auténticas políticas de género en su normativa interna, y que, además, trató de transponerlas en todo el Estado de México. Este ejemplo, sin embargo, hay que verlo como una excepción dentro de los grupos guerrilleros, y hay que tener en cuenta que en los demás casos la condición socio-cultural de las combatientes iba a resultar en todo momento un condicionante de los roles que cumplirían en la organización. Así, respecto a las mujeres indígenas su papel solía estar limitado a aquel que desempeñaban en sus sociedades. La aceptación de esos roles resultaba, además, conditio sine qua non para formar parte del grupo. Igualmente, las razones que las llevaban a alistarse en los grupos armados serán diferentes en función de su condición social; campesinas, estudiantes, indígenas o mujeres urbanas tienen singularidades en lo que respecta a su motivación.

\section{b) Guerrilleras en Colombia}

En Colombia, el ingreso de las mujeres en la guerrilla se produce en los años setenta del siglo XX, fecha en la que se comienza a permitir la inclusión de las mismas en los frentes de combate. La extensión del movimiento insurgente a las mujeres puede ser analizado desde dos ópticas diferentes: por un lado, atendiendo a los factores que estimularon el reclutamiento femenino por parte de los guerrilleros y, por otro, analizando los motivos que llevaron a las propias mujeres a convertirse en parte de la guerrilla. En el primero de los casos, según Ibarra Melo, se encuentran: los cambios en la naturaleza política de la lucha guerrillera, la percepción del peligro que implicaba perder el apoyo de la mujeres en caso de que se involucrasen en los partidos tradicionalistas y la difusión del pensamiento feminista, encauzado de manera que favoreciera los intereses de la izquierda en la lucha proletaria ${ }^{31}$.

Las mujeres comenzaban a sentirse parte de la revolución, lo que traía consigo un sentimiento de utilidad social que anteriormente no se encontraba al alcance de la población femenina de la época. No obstante, sus motivaciones, como ya hemos aludido, iban a depender decididamente de su condición social. En primer lugar, existía una razón romántica en las mujeres que voluntariamente aceptaron formar parte de la guerrilla cuando lo hicieron por propia convicción política, tratándose en su mayoría de mujeres urbanas con sentido de responsabilidad política y sensibilidad social, considerando que asumían un deber histórico, del cual el colectivo femenino no debía quedar fuera.

En segundo lugar, como propia convicción de individualidad, de decisión al margen de la autoridad patriarcal, razón que, al igual que las guerrilleras

${ }^{31}$ María Eugenia Ibarra Melo, "Guerrilleras y activistas por la paz en Colombia: incursión política y rupturas identitarias”, Pensamiento Psicológico, vol. 4, 11, (2008), págs. 65-84, pág. 73.

Araucaria. Revista Iberoamericana de Filosofia, Política y Humanidades, año 16, no 32. Segundo semestre de 2014. Pp. 383-397. ISSN 1575-6823 e-ISSN 2340-2199 doi: 10.12795/araucaria.2014.i32.19 
de Chiapas, les hacía ver la guerrilla como un espacio de libertad, donde sus deberes como mujer ya no se veían reducidos al matrimonio y a la maternidad, sería por tanto una razón emancipatoria ${ }^{32}$.

Una tercera motivación podría considerarse de venganza en algún caso. Cuando el alistamiento se producía en respuesta al estado de miseria y pobreza a las que su familia se había reducido por culpa de las estructuras institucionales del Estado.

En último lugar, puede atenderse a un deseo de igualdad masculinizada en el sentido de tener igual derecho y capacidad que el hombre para formar parte de un ejército, portar armas, etc ${ }^{33}$.

Sin embargo, con la narcotización del conflicto armado a partir de los años noventa del pasado siglo, las políticas de acceso al grupo se han transformado radicalmente y han pasado a estar repletas de singularidades, al igual que las motivaciones de las integrantes ${ }^{34}$. En la mayoría de los casos ya no se trata de una militancia política o ideológica, sino de un modo de conseguir un empleo. La guerrilla, así, como fuente de economía alternativa, mueve todos los engranajes de la misma a escala nacional ${ }^{35}$.

Debido a la larga duración del conflicto colombiano varias generaciones de una misma familia han conocido la guerrilla; sin embargo, al contrario que en el conflicto salvadoreño, las estructuras familiares no se han caracterizado por unirse al completo a la insurgencia, dándose en su mayoría incorporaciones individuales y, como norma general, en contra de la familia. Tampoco el campesinado ha sido una fuente incondicional de guerrilleros como sucedería en otros países. Al contrario, muchos de ellos se han mostrado esquivos a dejar sus cultivos y unirse a la guerrilla, causa por la que existe un numerosísimo grupo de campesinos desplazados, lo que ha convertido a Colombia en el segundo país del mundo con mayor número de refugiados o desplazados internos, después de Sudán ${ }^{36}$.

En cuanto a los retos actuales a los que se enfrentan las mujeres en la guerrilla colombiana, que actualmente representan entre un 35 y un $40 \%$ del total de guerrilleros de las $\mathrm{FARC}^{37}$, se encuentra el de formar parte de las negociaciones que actualmente están teniendo lugar entre la guerrilla y el

${ }^{32}$ Al respecto Vid., Arturo Alape, "La mujer en la guerrilla de las FARC", Archivo Chile, Centro de Estudios Miguel Enríquez. Documento en línea: www.archivochile.com/Mov.../mov mujeres/.../ MSdocmujotros0017.pdf.

${ }_{33}$ María Eugenia Ibarra Melo, "Guerrilleras y..., op. cit.

${ }^{34}$ Rocío Pineda, Mujeres entre la guerra y la paz: Lisístratas colombianas a las puertas de un nuevo milenio, Conferencia Presentada en el V Congreso Nacional de la Unión de Ciudadanas de Colombia, Cali, 12 de octubre de 1997, pág. 8.

${ }^{35}$ Eduardo Pizarro, Las FARC. De la autodefensa a la combinación de todas las formas de lucha, Bogotá, Tercer Mundo Editores, 1991, pág. 244.

36 Sobre este particular, vid. el análisis del ACNUR: http://www.acnur.org/t3/operaciones/ situacion-colombia/desplazamiento-interno-en-colombia/.

${ }^{37} \mathrm{http}$ //actualidad.rt.com/actualidad/view/108419-farc-guerrilleras-mujeres-portal. 
gobierno, lo que les permitiría ganar así un espacio político en el movimiento guerrillero. Por su parte, el gobierno colombiano ha nombrado a una mujer como negociadora de su equipo ${ }^{38}$.

Por otro lado, hay cuestiones muy preocupantes relacionadas con la violencia basada en el género en el interior de los grupos guerrilleros, aunque la información es limitada debido a la clandestinidad intrínseca a las FARC. No obstante, sí existen diversos testimonios de ex guerrilleras que denuncian abortos forzados en el seno del grupo, cuestión que urge abordar por parte de todos los actores de la sociedad colombiana, de las asociaciones civiles, tanto nacionales como internacionales, así como de las investigaciones académicas.

\section{Conclusiones}

Son múltiples las causas por las que las mujeres deciden entrar en los grupos guerrilleros irregulares ${ }^{39}$ y luchar activamente en los frentes de combate. En ocasiones su acceso no resulta fácil, y en otros casos, es su convivencia con el grupo la que se ve truncada, por reflejar los estereotipos de género existentes en los tiempos o lugares de $\mathrm{paz}^{40}$.

Sin embargo, a veces la guerrilla ha supuesto una suerte de avance para la identidad de las mujeres, a las que se ha desbiologizado de sus componentes de hogar y paz $^{41}$. En el caso de Colombia, las mujeres de los grupos guerrilleros tienen atribuidos en su mayoría roles arquetípicos de género, como las labores del hogar y los servicios sexuales, lo que no ayuda a la emancipación que podría derivarse de la asunción del rol de guerrillera. Resulta especialmente alarmante el uso de técnicas coactivas para la militarización de niñas, así como a su desmovilización de los grupos guerrilleros, al igual que los casos de abortos forzados. No obstante, también existen ejemplos de cierta emancipación en el interior de las FARC, por lo que no podemos considerar la existencia de una tendencia única.

Los grupos guerrilleros se han caracterizado por no anteponer ningún asunto a la propia revolución. Sin embargo, algunos de ellos han asumido las reivindicaciones de género como parte de la justicia social, derivada quizá de una concepción marxista de la igualdad, donde hombres y mujeres se rigen por

\footnotetext{
${ }^{38}$ http://espanol.cntv.cn/20131118/102545.shtml.

39 V. Mosquera; C. J. Holguín, El componente de género en los movimientos guerrilleros desde la percepción de excombatientes, Cali, Universidad del Valle, 2001.

40 Vid., María Eugenia Ibarra Melo, Transformaciones identitarias de las mujeres como resultado de su participación política en las guerrillas y en las acciones colectivas por la paz en Colombia, Tesis Doctoral, Universidad Complutense de Madrid, 2007, pág. 531. Accesible en: http://eprints. ucm.es/7522/.

41 Donny Meertens, "Género y conflicto armado en Colombia: aproximación a un diagnóstico", en Mujer y conflicto armado, Secretaría de Mujer y Género, Consejería Presidencial para la Política Social, Bogotá, 1995.
} 
el mismo patrón. Esto ha hecho posible que las guerrilleras se encuentren en muchos casos en un escalón social superior al que correspondería a las mujeres de sus respectivas sociedades patriarcales, asumiendo nuevos roles que antes eran únicamente atribuidos a los hombres de su comunidad, pero también dotándolas de conciencia y autonomía propia en las reivindicaciones de género.

Especialmente con las guerrilleras del EZLN, hemos podido observar cómo se han agrupado en torno al género y han logrado llevar a la agenda política nacional estas cuestiones, sirviéndose del grupo guerrillero como plataforma formativa, social e, incluso, política. Las repercusiones de estas reivindicaciones han tenido efecto también en el exterior del grupo, lo que convierte a las guerrilleras en portavoces de la discriminación de las mujeres y primeras en adquirir las herramientas necesarias para su reivindicación político-social.

En el lado negativo, también hemos observado justo lo contrario, fundamentalmente en el caso de las FARC: la incentivación de los roles tradicionalmente femeninos en la participación en el grupo guerrillero, a través de la distribución de tareas con arreglo a estereotipos y, lo que es más preocupante, el uso de la coacción o violencia para reclutar a las mujeres o para obtener contraprestaciones de orden doméstico, reproductivo o sexual por parte de los combatientes de su propio grupo ${ }^{42}$.

Por tanto, debemos concluir que no existe un modelo de guerrillera, sino dos dinámicas predominantes y contrarias: por un lado, la liberación de las mujeres dentro del grupo guerrillero, lo que viene a incidir posteriormente en su posición en la sociedad en general; $y$, por otro, la acentuación de su sumisión a la figura del hombre como figura de poder, lo que sitúa a las mujeres guerrilleras en una posición de tremenda susceptibilidad en cuanto a la violencia basada en el género y otras conductas de coacción y minusvaloración de las aptitudes como guerrillera.

Pese a la existencia de estas dos dinámicas (emancipación/sumisión) no podemos concluir que cada una de ellas represente fielmente los modelos expuestos (EZLN/FARC), sino que en ambos encontramos variables de ambas tendencias. En consecuencia, no podemos hablar de modelos inequívocos, sino de tendencias, ya que no se trata de dinámicas excluyentes sino complementarias. Los roles de género no pueden sino persistir en una sociedad global marcadamente desigual, donde la equiparación social de las mujeres con los hombres no es una realidad sino un reto. El modelo emancipatorio ha conseguido que las mujeres guerrilleras avancen con respecto a la situación de extrema discriminación existente en el exterior del grupo, lo que no supone la consecución de una igualdad real y efectiva en su consideración política, jurídica, militar o social.

${ }^{42}$ Es necesario destacar igualmente algunos ejemplos de mujeres víctimas de la guerrilla que, en su condición de mujer, han sufrido la violencia de una manera específica. Es el caso de Ingrid Betancourt o Clara Largo, secuestradas por la guerrilla colombiana en 2002 y liberadas en 2008. En el caso de Clara Largo, además, tuvo un hijo durante su cautiverio. 


\section{Referencias bibliográficas:}

Arturo Alape, "La mujer en la guerrilla de las FARC", Archivo Chile, Centro de Estudios Miguel Enríquez. Documento en línea: www.archivochile.com/ Mov.../mov_mujeres/.../MSdocmujotros0017.pdf.

Christine Chinkin, "A Gendered Perspective to the International Use of Force", Australian Yearbook of International Law, 12, (1988-1989), págs. 279293.

Donny Meertens, "Género y conflicto armado en Colombia: aproximación a un diagnóstico", Mujer y conflicto armado, Secretaría de Mujer y Género, Consejería Presidencial para la Política Social, Bogotá, 1995.

Eduardo Pizarro, Las FARC. De la autodefensa a la combinación de todas las formas de lucha, Bogotá, Tercer Mundo Editores, 1991, pág. 244.

Evelyn Cherpack, "Las mujeres en la independencia", en [Las mujeres en la historia de Colombia: Tomo II Mujeres y Sociedad, Santa Fé de Bogotá, Consejería Presidencial para la Política Social].

Francisco Moreno Gómez, F., "Guerrilleras y Enlaces: Las mujeres en la resistencia antifranquista”, Andalucía en la Historia, 25, (2009), págs. 2629.

Guiomar Rovira, Mujeres de Maiz. La voz de las indígenas de Chiapas y la rebelión zapatista, Barcelona, Virus, Barcelona, 1999, pág. 236.

Jane Jaquette, "Los movimientos de mujeres y las transiciones democráticas en América Latina", en [Magdalena León, coord.: Mujeres y participación politica. Avances y desafíos en América Latina, Bogotá, Tercer Mundo Editores, 1994], págs. 117-139.

José Ramón Diego Aguirre, Historia del Sáhara español: la verdad de una traición, Madrid, 1998, pág. 879.

María Eugenia Ibarra Melo, "Guerrilleras y activistas por la paz en Colombia: incursión política y rupturas identitarias”, Pensamiento Psicológico, vol. 4, 11, (2008), págs. 65-84.

María Eugenia Ibarra Melo, Mujeres e insurrección en Colombia: reconfiguración de la identidad femenina en la guerrilla, Cali, Pontificia Universidad Javeriana, 2009, pág. 240.

Olivia Bennet; Jo Bexley; Kitty Warnok, Arms to Fight, Arms to Protect: Women speaks out about conflict, London, Panos Publications, London, 2001, pág. 288.

Rocío Pineda, Mujeres entre la guerra y la paz: Lisistratas colombianas a las puertas de un nuevo milenio, Conferencia Presentada en el V Congreso Nacional de la Unión de Ciudadanas de Colombia, Cali, 12 de octubre de 1997, pág. 8. 
Sarri Vourisalo-Tiitinen, "Un análisis crítico del discurso sobre el problema del ser mujer e indígena en México-La respuesta de las mujeres zapatistas a la reestructuración neoliberal", en [Género y globalización en América Latina: décimo aniversario de la Red Haina (1996-2006), Göteborg, Universidad de Göteborg, 2007], pág. 197.

Sarri Vuorisalo-Tiitinen, ¿Feminismo indígena? Un análisis crítico del discurso sobre los textos de la mujer en el movimiento zapatista 19942009, Helsinki, University of Helsinki, 2011, pág. 310.

Signe Arnfred, "Women in Mozambique: Gender Struggle and Gender Politics", Review of African Political Economy, vol. 15, 41, (1988), págs. 5-16.

Stephanie Urdang, And Still They Dance: Women, War, and the Struggle for Change in Mozambique, London, Earthscan, 1989, pág. 256.

Tanya Lyons, "Guerrilla Girls and Women in the Zimbabwean National Liberation Struggle", en [ Jean Allman; Susan Geiger; Nakanyike Musisi, coords.: Women in African Colonial Histories, Bloomington, Indiana University Press, 2002], pág. 338.

Tanya Lyons, Guns and Guerrilla Girls. Women in the Zimbabwean Liberation Struggle, Asmara, Africa World Press, 2004, pág. 319. 
